\title{
Bi-Level Noninvasive Ventilation in Neonatal Respiratory Distress Syndrome. A Systematic Review and Meta-Analysis
}

\author{
Anne Lee Solevåga Po-Yin Cheung ${ }^{b, c, d}$ Georg M. Schmölzer ${ }^{b, c}$ \\ aDepartment of Paediatric and Adolescent Medicine, Oslo University Hospital, Oslo, Norway; ${ }^{b}$ Department of \\ Pediatrics, University of Alberta, Edmonton, $A B, C a n a d a ;{ }^{~} C e n t r e$ for the Studies of Asphyxia and Resuscitation, \\ Royal Alexandra Hospital, Edmonton, $A B$, Canada; ${ }^{d}$ Department of Pharmacology, University of Alberta, \\ Edmonton, $\mathrm{AB}$, Canada
}

\begin{abstract}
Keywords
Continuous positive airway pressure $\cdot$ Bi-level positive airway pressure $\cdot$ Nasal intermittent positive pressure ventilation · Premature infant · Respiratory distress syndrome $\cdot$ Bronchopulmonary dysplasia $\cdot$ Meta-analysis
\end{abstract}

\begin{abstract}
Background: Bi-level noninvasive ventilation (NIV) has been used in respiratory distress syndrome (RDS) as primary treatment, post-extubation, and to treat apnea. This review summarizes studies on bi-level NIV in premature infants with RDS. Nonsynchronized nasal intermittent positive pressure ventilation (nsNIPPV) and synchronized NIPPV (SNIPPV) use pressure settings $\geq$ those used during mechanical ventilation (MV), and biphasic continuous positive airway pressure (BiPAP) use two nasal continuous positive airway pressure (NCPAP) levels $\leq 4 \mathrm{~cm} \mathrm{H_{2 }}$ O apart. Methods: A systematic review (Medline OVID and Pubmed) and meta-analysis of randomized controlled trials. Primary outcomes were bronchopulmonary dysplasia (BPD) and mortality. Secondary outcomes included NIV failure (intubation) and extubation failure (re-intubation). Data were pooled using a fixed-effects model to calculate the relative risk (RR) with $95 \%$ confidence interval $(\mathrm{Cl})$ between NIV modes (RevMan v 5.3, Co-
\end{abstract}

penhagen, Denmark). Results: Twenty-four randomized controlled trials that largely did not correct for mean airway pressure (MAP) and used outdated ventilators were included. Compared with NCPAP, both nsNIPPV and SNIPPV resulted in less re-intubation (RR 0.88 with $95 \% \mathrm{Cl}(0.80,0.97)$ and $\operatorname{RR} 0.20(0.10,0.38)$, respectively) and $B P D(\operatorname{RR} 0.69(0.49,0.97)$ and RR $0.51(0.29,0.88)$, respectively). nsNIPPV also resulted in less intubation (RR $0.57(0.45,0.73)$ versus NCPAP, with no difference in mortality. One study showed less intubation in BiPAP versus NCPAP. Conclusions: Bi-level NIV versus NCPAP may reduce $M V$ and $B P D$ in premature infants with RDS. Studies comparing equivalent MAP utilizing currently available machines are needed.

(c) 2021 The Author(s).
Published by S. Karger AG, Basel

\section{Introduction}

Neonatal intensive care units use bi-level noninvasive ventilation (NIV) increasingly to avoid invasive mechanical ventilation (MV) [1-3]. The large heterogeneity of more than 20 years of bi-level NIV studies has resulted in insufficient evidence to make recommendations for indications, choice of modality, and settings $[2,4]$. karger@karger.com www.karger.com/neo

Karger $\stackrel{\text { ' }}{5}$

BOPEN ACCESS
(C) 2021 The Author(s)

Published by S. Karger AG, Basel

This is an Open Access article licensed under the Creative Commons Attribution-NonCommercial-4.0 International License (CC BY-NC) (http://www.karger.com/Services/OpenAccessLicense), applicable to the online version of the article only. Usage and distribution for commercial purposes requires written permission.
Anne Lee Solevåg

Department of Paediatric and Adolescent Medicine, Oslo University Hospital PO Box 4950 Nydalen

NO - 0424 Oslo (Norway)

a.l.solevag@medisin.uio.no 
Theoretical advantages of NIV over invasive MV in premature infants with respiratory distress syndrome (RDS) include less bronchopulmonary dysplasia (BPD) [5]. Mechanisms of action of nasal continuous positive airway pressure (NCPAP) include improved oxygenation and ventilation-perfusion matching secondary to increased functional residual capacity (FRC) [6]. Bi-level NIV, that is, NIV with alternating pressure, theoretically adds benefits of increased mean airway pressure (MAP), improved alveolar recruitment, FRC and airway diameter, as well as atelectasis prevention $[7,8]$. Controversy exists whether to synchronize pressure peaks with spontaneous breathing [9], and about the reliability [10] of different synchronization methods in bi-level NIV. However, it has been speculated that nonconventional gas-exchange might occur during bi-level NIV $[10,11]$, potentially limiting the importance of synchronization.

\section{Different Modes and Systems for Bi-Level Noninvasive Ventilation Delivery}

Although the terms nasal intermittent positive pressure ventilation (NIPPV) and bi-level positive airway pressure (BiPAP) has been used interchangeably [12], NIPPV is frequently associated with pressure settings equal to or higher than those used during MV (positive inspiratory pressure $14-24$, positive end-expiratory pressure 3-6 $\mathrm{cm} \mathrm{H}_{2} \mathrm{O}$ ), $\mathrm{T}_{\text {high }} / \mathrm{T}_{\mathrm{i}} 0.3-0.5 \mathrm{~s}$ and rates $10-60 / \mathrm{min}$. "BiPAP" is more commonly used when the infant breathes independently of two CPAP levels that are $\leq 4 \mathrm{~cm} \mathrm{H}_{2} \mathrm{O}$ apart [13]. $\mathrm{T}_{\text {high }} 0.6-1.0 \mathrm{~s}$ and rates of $10-30 / \mathrm{min}$ are frequently used. It has been speculated that BiPAP treatment might provide a higher MAP without potential side effects of a high continuous distending pressure [14]. However, it is controversial whether a high continuous distending pressure may cause harm [15]. The NIV system/driver is likely to influence NIV effectiveness [10] including FRC [16], e.g., the CareFusion/Viasys/Vyaire Infant Flow SiPAP that was used in numerous studies of bi-level NIV, was developed to reduce expiratory resistance and airway pressure fluctuations [17].

Despite widespread use $[1-3,18,19]$, bi-level NIV is not considered evidence-based treatment. The aim of this review and meta-analysis was to summarize studies in premature infants with RDS to identify the knowledge gaps. The primary research question was "In premature infant with RDS, how does different modes of bilevel NIV influence BPD and mortality, compared to NCPAP?"

\section{Methods}

We aimed to identify a broad spectrum of studies, reflecting the heterogeneity of patients with RDS eligible for bi-level NIV including a) Infants who are primarily placed on NIV, and b) Infants who have been intubated and then extubated to NIV.

The systematic review was carried out according to the PRISMA statement [20] and registered in PROSPERO (CRD 42020182190). We searched Medline OVID using search terms including Infant, Newborn OR Infant, Premature AND Noninvasive Ventilation OR bibap.mp OR nippv.mp. A PubMed search included: Infant, Newborn OR Infant, Premature AND Noninvasive Ventilation OR bibap.mp OR nippv.mp NOT child NOT pediatric NOT bronchiolitis NOT PICU NOT high frequency NOT high flow. The last search was performed September 25th 2020.

We searched the reference lists of retrieved studies and performed searches on relevant authors. Randomized controlled trials (RCT) were included, not review papers and commentaries. We only included papers in English, and similar to Ekhaguere et al. [21], we excluded conference abstracts. No limits on publication date were applied.

ALS and PYC independently assessed the quality of the studies using the following criteria: blinding of randomization, blinding of intervention, completeness of follow-up, and blinding of outcome measurement. We assessed risk of bias using the criteria outlined in the Cochrane Handbook for Systematic Reviews of Interventions [22]. The quality of the evidence was evaluated by Grading of Recommendations Assessment, Development, and Evaluation (GRADE) approach [23] and GRADEpro Guideline Development Tool Software (McMaster University, developed by Evidence Prime, Inc.). Disagreements were resolved by a 3 rd assessor (GS).

For the primary outcomes, BPD and mortality, and secondary outcomes NIV-/extubation failure and MV-/NIV duration, we analyzed trials using risk ratio (RR) with $95 \%$ confidence interval for dichotomous outcomes, and mean difference for continuous outcomes. Heterogeneity was assessed using the Q statistic and $I^{2}$ [24]. The meta-analyses were performed with the Review Manager software v5.3 (The Nordic Cochrane Center, The Cochrane Collaboration, Copenhagen, Denmark). We used only published data. Thus, outcomes published as median (not mean), for example, duration of MV/NIV, were not included in the meta-analysis. Due to a large heterogeneity of surfactant administration protocols, MV modalities and settings, characteristics of the study population, duration of MV before extubation and weaning criteria from $M V$, studies where the infants had previously been on MV were excluded from the meta-analysis of the primary outcomes.

\section{Results}

The searches retrieved 304 citations. Of these, we included 24 RCTs (PRISMA flow chart and see online suppl. Table 1; for all online suppl. material, see www.karger. com/doi/10.1159/0005514637). 


\subsection{Duration of mechanical ventilation (hours) as a composite of before and after non-invasive ventilation treatment}

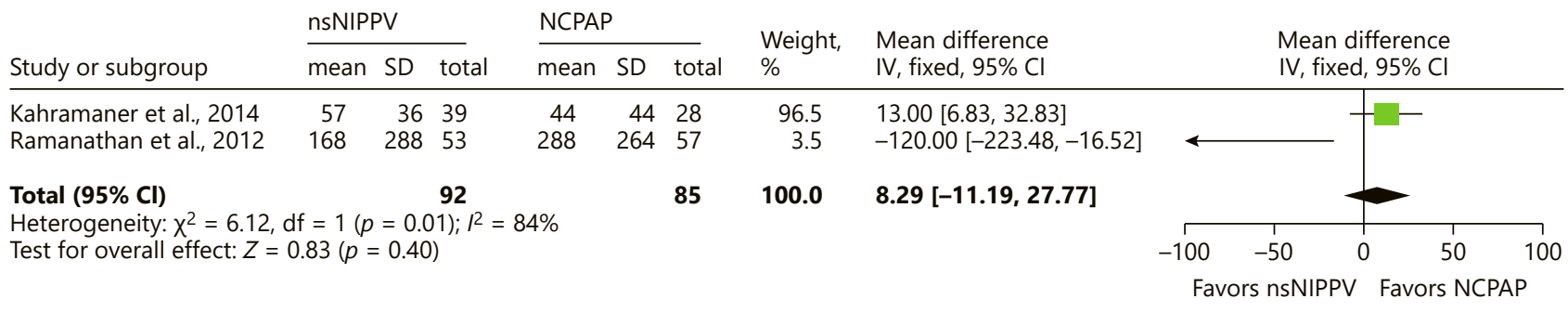

1.2 Bronchopulmonary dysplasia

Risk difference nsNIPPV vs NCPAP $-0.05[-0.09,-0.00]$, number needed to treat $($ NNT) $=21$

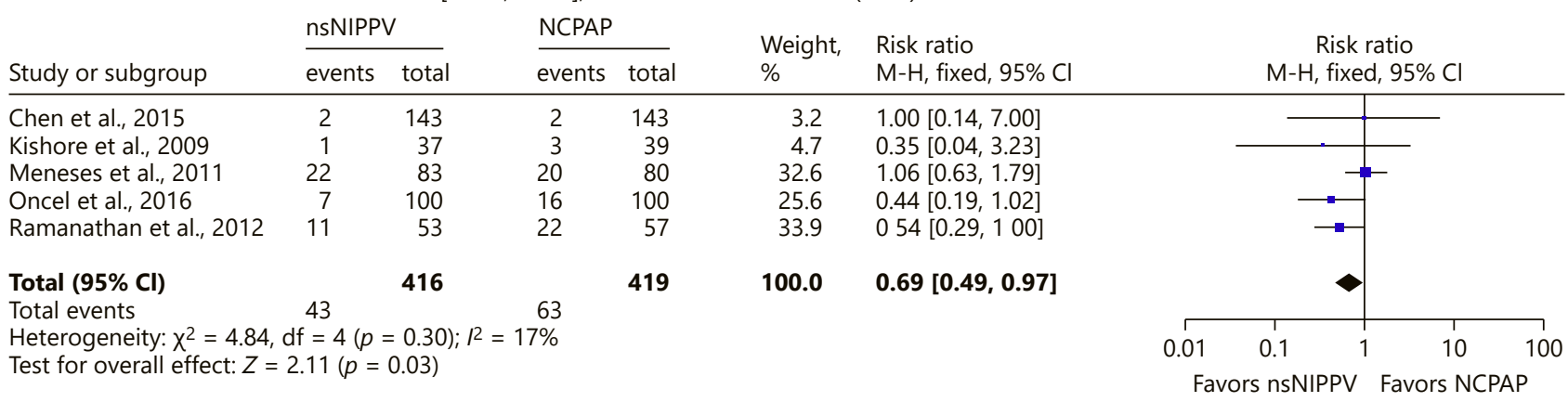

1.3 Extubation failure

Risk difference nsNIPPV vs NCPAP $-0.06[-0.11,-0.01]$, NNT = 19

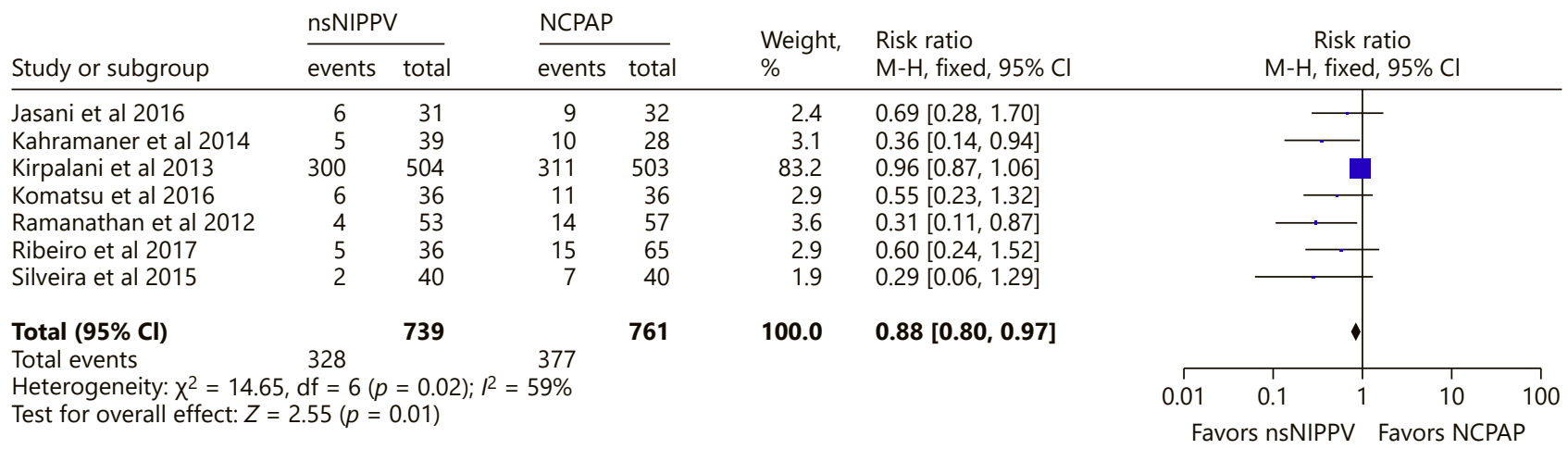

1.4 Mortality

Risk difference nsNIPPV vs NCPAP $-0.02[-0.05,0.01]$

\begin{tabular}{|c|c|c|c|c|c|c|}
\hline \multirow[b]{2}{*}{ Study or subgroup } & \multicolumn{2}{|c|}{ nsNIPPV } & \multicolumn{2}{|l|}{ NCPAP } & \multirow{2}{*}{$\begin{array}{l}\text { Weight, } \\
\%\end{array}$} & \multirow{2}{*}{$\begin{array}{l}\text { Risk ratio } \\
\mathrm{M}-\mathrm{H} \text {, fixed, } 95 \% \mathrm{Cl}\end{array}$} \\
\hline & events & total & events & total & & \\
\hline Armanian et al., 2014 & 2 & 44 & 1 & 54 & 1.6 & $2.45[0.23,26.18]$ \\
\hline Chen et al., 2015 & 7 & 143 & 12 & 143 & 21.4 & $0.58[0.24,1.44]$ \\
\hline Kishore et al., 2009 & 5 & 37 & 9 & 39 & 15.6 & $0.59[0.22,1.59]$ \\
\hline Meneses et al., 2011 & 22 & 100 & 26 & 100 & 46.4 & $0.85[0.52,1.39]$ \\
\hline Oncel et al., 2016 & 4 & 100 & 6 & 100 & 10.7 & $0.67[0.19,2.29]$ \\
\hline Ramanathan et al., 2012 & 1 & 53 & 1 & 57 & 1.7 & $1.08[0.07,16.76]$ \\
\hline Ribeiro et al., 2017 & 1 & 36 & 2 & 64 & 2.6 & $0.89(0.08,9.47]$ \\
\hline Silveira et al., 2015 & 0 & 40 & 0 & 40 & & Not estimable \\
\hline Total $(95 \% \mathrm{Cl})$ & & 553 & & 597 & 100.0 & $0.76[0.53,1.10]$ \\
\hline
\end{tabular}

Total events $42 \quad 57$

Heterogeneity: $x^{2}=1.84, \mathrm{df}=6(p=0.93) ; l^{2}=0 \%$

Test for overall effect: $Z=1.47(p=0.14)$

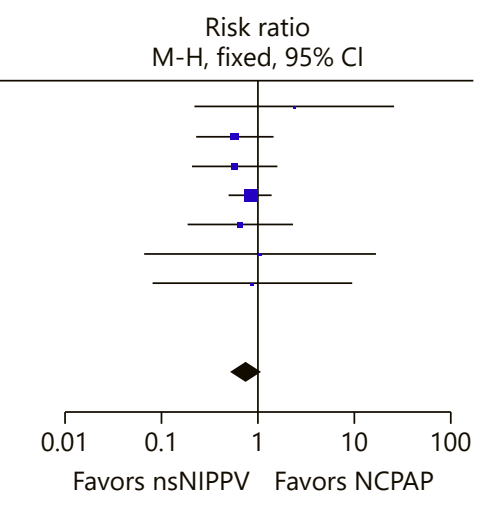

1

(Figure continued on next page.) 
1.5 Non-invasive ventilation failure

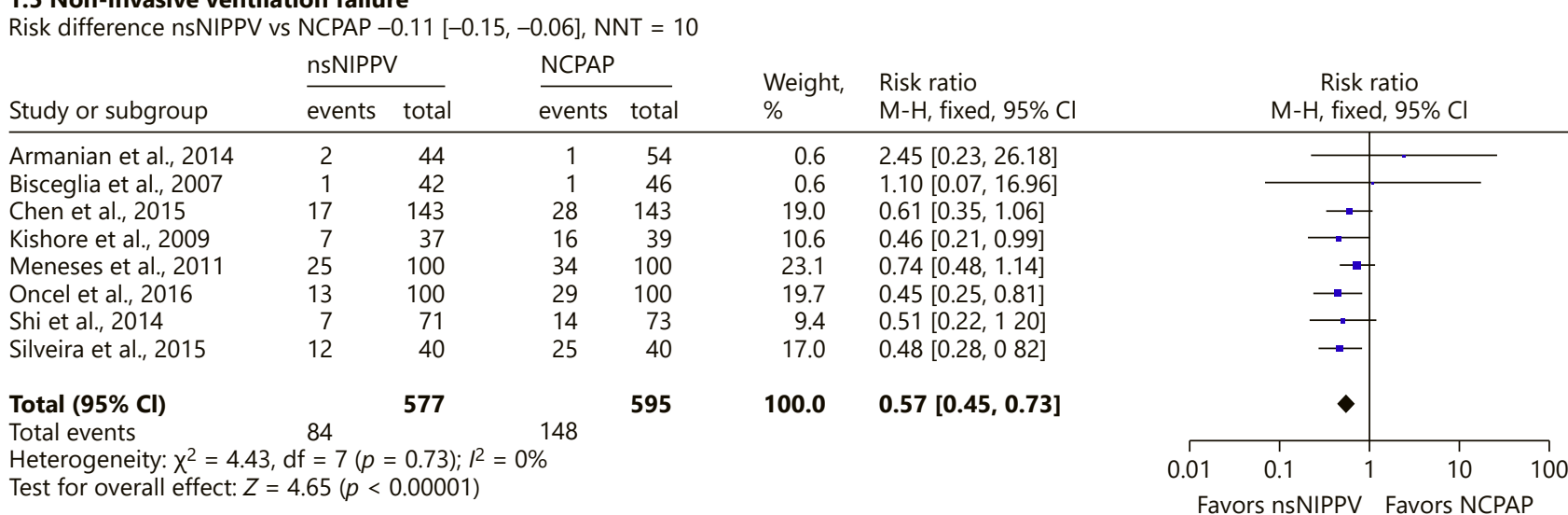

1.6 Duration of non-invasive ventilation (hours)



Fig. 1. nsNIPPV versus NCPAP. nsNIPPV, nonsynchronized nasal intermittent positive pressure ventilation; NCPAP, nasal continuous positive airway pressure.

\section{Included Studies}

Studies Comparing Nonsynchronized Nasal

Intermittent Positive Pressure Ventilation versus

Nasal Continuous Positive Airway Pressure $(N=15)$

Most studies included very and moderately preterm infants (GA 28-34 weeks) with very low birth weight $(<1,500 \mathrm{~g})$ (online suppl. Table 1$)$. Eight studies examined nsNIPPV versus NCPAP as primary treatment $[7,25-$ $31]$, whereas 5 were in previously intubated infants [32$36]$, and two a combination of primary and post-extubation NIV-treatment $[37,38]$.

BPD was lower (47 fewer per 1.000) with similar mortality with nsNIPPV versus NCPAP. There were significantly less primary NIV failure (107 fewer per 1.000) and extubation failure (59 fewer per 1.000) in nsNIPPV versus NCPAP. There was no difference in NIV duration or MV duration (Fig. 1).

In conclusion, nsNIPPV results in less BPD (moderate-quality evidence) and similar mortality (moderate-quality evidence) compared with NCPAP. Primary
NIV- and extubation failure were less in nsNIPPV versus NCPAP (moderate-quality evidence). For the outcomes MV and NIV duration, the heterogeneity of the studies was large $\left(I^{2}>50 \%\right)$, potentially due to different MV modalities and settings, MV weaning criteria, as well as heterogeneity of the patient population. This evidence was downgraded to low quality due to inconsistency.

Studies Comparing Synchronized Nasal Intermittent

Positive Pressure Ventilation versus Nasal

Continuous Positive Airway Pressure $(N=5)$

Most studies included very and moderately preterm infants (GA 28-34 weeks) with very low birth weight. Only one examined NIV as primary RDS treatment [39]. The study by Moretti et al. [40] reported MV and NIV days in median (range) and was not included in the metaanalysis for these outcomes. Friedlich et al. [41] reported the length of initial MV, that is, a baseline not an outcome variable. Thus, MV duration as an outcome could not be subject to meta-analysis. 


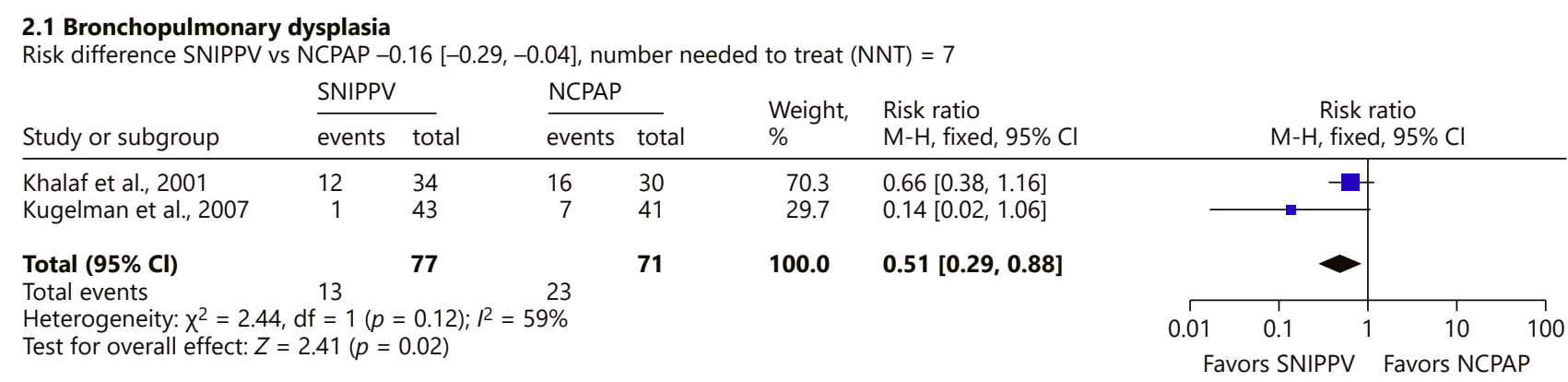

\subsection{Extubation failure}

Risk difference SNIPPV vs NCPAP $-0.32[-0.43,-0.22]$, NNT = 3



\subsection{Non-invasive ventilation failure}

Risk difference SNIPPV vs NCPAP $-0.23[-0.43,-0.03]$, NNT $=5$

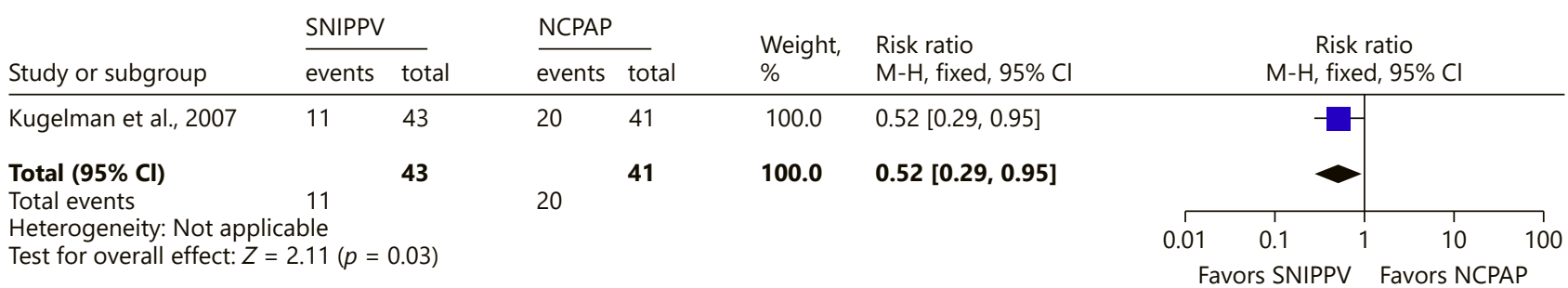

Fig. 2. SNIPPV versus NCPAP. SNIPPV, synchronized intermittent positive pressure ventilation; NCPAP, nasal continuous positive airway pressure.

BPD was lower (159 fewer per 1,000) in SNIPPV versus NCPAP. Mortality could not be assessed. There was less primary NIV (234 fewer per 1,000) (only one study [39]) and extubation failure (321 fewer per 1,000$)[8,40-$ 42] in SNIPPV versus NCPAP (Fig. 2). In conclusion, SNIPPV may prevent primary NIV-and extubation failure compared to NCPAP, and reduce BPD (moderatequality evidence).
Studies Comparing Biphasic Continuous Positive Airway Pressure versus Nasal Continuous Positive Airway Pressure $(N=4)$

Most studies included very and moderately preterm infants (GA 28-34 weeks) with very low birth weight. All studies, but one [43] used the Infant flow SiPAP or the Infant flow advance. Only Victor et al. [44] used equivalent MAP in comparison of the two modes. Only Victor et al. [44] reported NIV duration. Thus, this outcome was not included in the meta-analysis.

There was no difference in BPD $[12,43,45]$ or mortality $[12,45]$. The meta-analysis revealed no difference in 
3.1 Duration of mechanical ventilation (days) after non-invasive ventilation failure

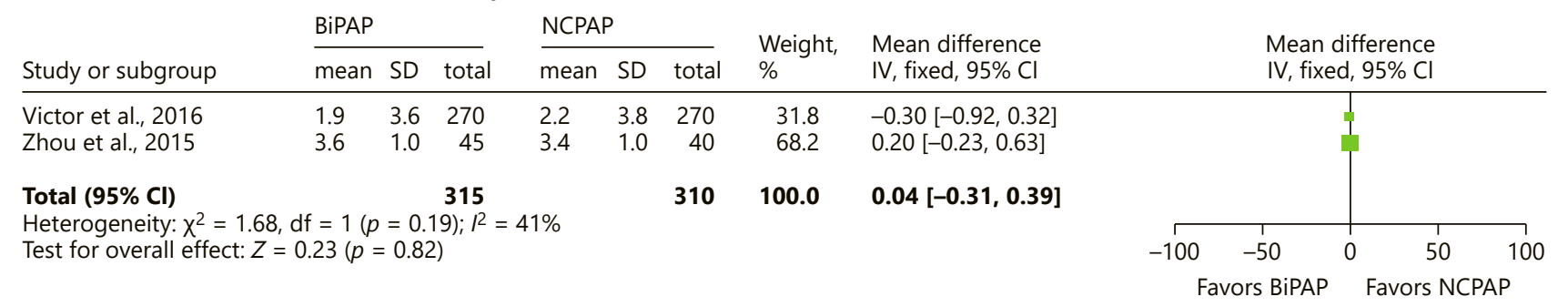

\subsection{Bronchopulmonary dysplasia}

Risk differenceBiPAP vs NCPAP $-0.00[-0.09,0.08]$

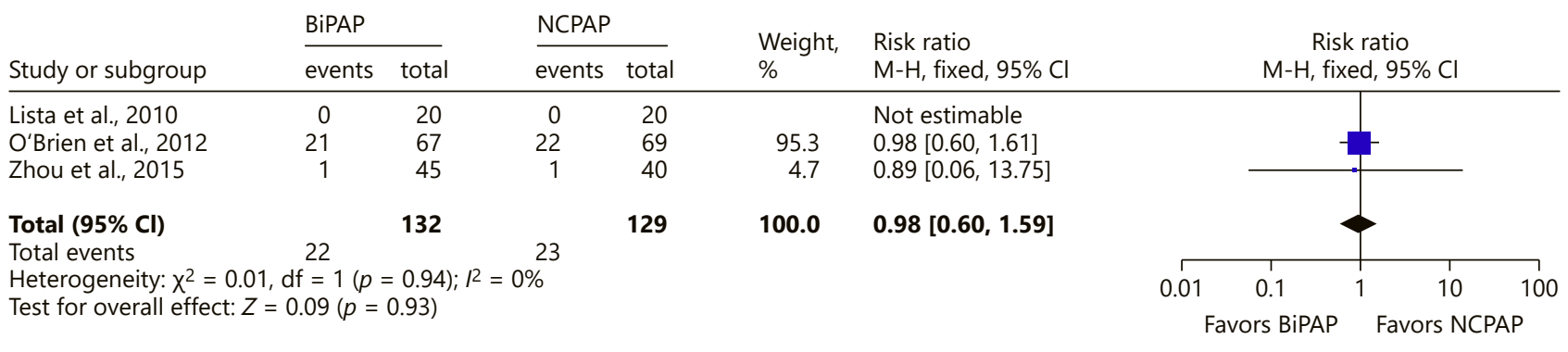

\subsection{Extubation failure}

Risk differenceBiPAP vs NCPAP $-0.00[-0.07,0.07]$

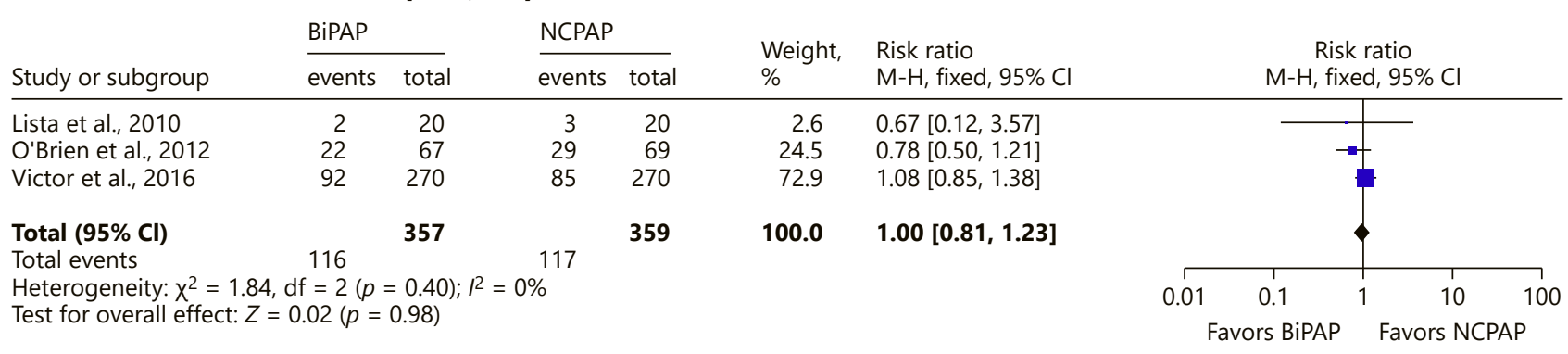

3.4 Mortality

Risk differenceBiPAP vs NCPAP $-0.02[-0.09,0.04]$

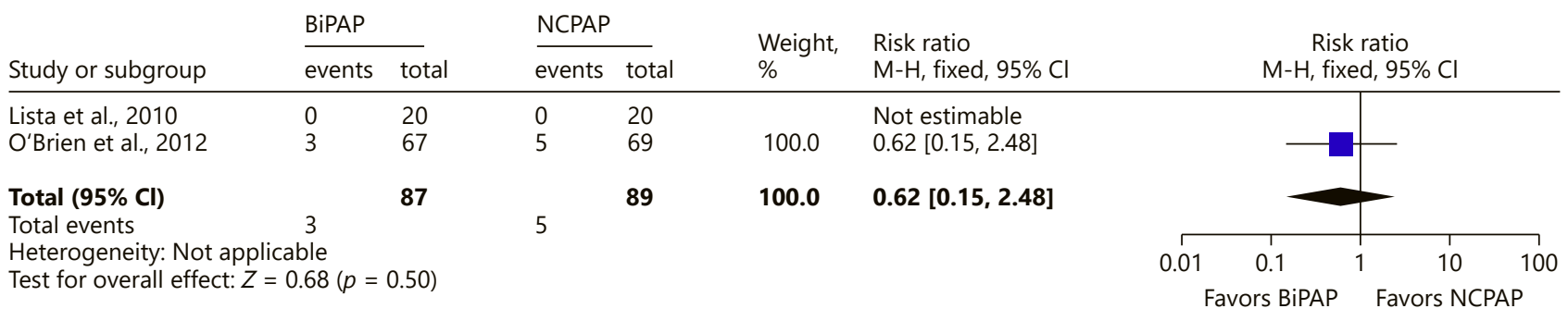

Fig. 3. BiPAP versus NCPAP. NCPAP, nasal continuous positive airway pressure; BiPAP, bi-level positive airway pressure.

extubation failure in BiPAP versus NCPAP. MV duration was not different with BiPAP versus NCPAP (Fig. 3). Zhou et al. [43] used the Fabian DuoPAP and found less primary NIV failure, improved oxygenation and ven- tilation, and less need for MV and complications when BiPAP was used as primary RDS treatment.

In conclusion, insufficient evidence exists and we cannot conclude whether BiPAP improves RDS treatment 





compared with NCPAP. For the outcome MV duration, the heterogeneity of the studies was large $\left(I^{2}>50 \%\right)$.

\section{Quality of the Evidence}

In all the included RCTs, clinicians and investigators were aware of the intervention received by each infant (bi-level NIV or NCPAP). In addition, most studies are dated and used machines that are now largely obsolete. Thus, due to a lack of masking of the interventions and indirectness, we graded the quality of evidence for all outcomes (duration of NIV and MV, BPD, extubation failure, NIV failure, and mortality) as moderate to low (Table 1).

\section{Discussion}

NIPPV and BiPAP have been investigated for their potential to augment the benefits of NCPAP in premature infants with RDS. This meta-analysis aimed to distinguish between the individual modalities/modes of bi-level NIV (nonsynchronized NIPPV, synchronized NIPPV, Bi-level CPAP), often used under a single acronym in the literature (e.g., NIV or NIPPV), or included in the same study group, although with significant technical differences. These important differences are explained in our review, which distinguishes the current article from previous reviews and meta-analyses.

The quality of the evidence in the meta-analysis was moderate to low, mainly due to a lack of blinding of intervention and outcome measurement. For some outcomes, there was inconsistency across studies. We found that nsNIPPV versus NCPAP reduced BPD but not mortality and reduced primary NIV- and extubation failure among premature infants with RDS. SNIPPV versus NCPAP reduced BPD, but mortality could not be assessed. SNIPPV versus NCPAP reduced primary NIVand extubation failure among premature infants with RDS. Most studies used the InfantStar ventilator and a Graseby capsule for synchronization. Insufficient evidence exists regarding BiPAP versus NCPAP.

A limitation of the meta-analysis is that non-English language reports and RCTs presented in conferences were excluded. This may have introduced bias, particularly as RCTs that were only presented as conference abstracts may more likely have demonstrated negative results, that is, no difference between treatment modalities. We did not obtain raw data from the authors of the included studies. The large pragmatic study by Kirpalani et al. [37] included 241 infants that received "mainly
BiPAP" and 215 that received "mainly NIPPV"; the remaining 41 infants had mixed exposures. Different NIV strategies, devices, and settings represented challenges to the inclusion of the study data in the meta-analysis. Strengths of our review include its comprehensiveness and stratification according to different bi-level NIV-modes.

Randomized controlled trials of bi-level NIV are very low to moderate quality, predominantly due to a lack of blinding to the intervention. Although studies have compared NIPPV with BiPAP, there is disagreement whether NIPPV and BiPAP should be viewed as separated entities [10]. Importantly, most studies did not compare the modalities at equal MAP, a variable that has been shown to have important impact on the failure rate of NIV [46].

The included studies span a large time period with varying approaches to surfactant treatment and neonatal care in general. It is uncertain how these data are transferable to modern practice with, for example, increasing use of less invasive surfactant administration/minimally invasive surfactant therapy. Also, the studies that demonstrated a benefit of NIPPV used machines that are now largely obsolete $[2,10,47]$. The Infant flow SiPAP used in most BiPAP studies delivers a pressure $\leq 10 \mathrm{~cm} \mathrm{H}_{2} \mathrm{O}$. Its predecessor, the Infant flow advance delivered $\leq 11 \mathrm{~cm}$ $\mathrm{H}_{2} \mathrm{O}$. Newer machines and techniques are becoming available and they need scientific evidence, policies, and staff training to be properly utilized. Medin CNO (Medical Innovations $\mathrm{GmbH}$, Puchheim, Germany), Fabian DuoPAP (Acutronic Medical Systems AG, Hirzel, Switzerland), and similar machines are operated through pressure settings, not flow settings like the Infant flow machines. One study using the Fabian DuoPAP was identified, with a hybrid between NIPPV and BiPAP settings used. The latest Fabian DuoPAP model is equipped with a NIV Trigger hot-wire flow sensor.

Inherent to NIV with short bi-nasal prongs or nasal mask is leak from the nose and mouth, which may limit its effectiveness. All included studies used bi-nasal or nasopharyngeal prongs/tubes. Few authors $[34,40,44]$ addressed leak and some used a chin strap $[7,12,28]$ to achieve the intended pressures. Two studies specifically stated that "No precautions were taken to avoid leakage from the mouth" $[34,40]$.

\section{Future Research Directions}

The significant morbidity and mortality resulting from invasive MV of premature infants with RDS remain an unresolved challenge. NCPAP is beneficial but fails in almost half of (extremely) premature infants in some centers. Other methods for keeping these infants off MV are 
thus urgently required. One or more bi-level NIV modes might be an option, and may also prove to be relevant in low-resource settings where MV is not available. As MV is associated with intensive care needs including iv sedation, parenteral nutrition, and hemodynamic support, bilevel NIV may be less costly and might require less staffing compared with MV treatment. More research on health economic aspects of bi-level NIV is needed.

Future studies should compare the NIV modalities at equal MAP in order to discern if it is the phasic pressure changes or the higher MAP that is responsible for the apparent benefit of bi-level NIV. More single-institution studies, preferably during the adoption of new machines and/or policies and procedures, using quality improvement methodology would be useful. We speculate that with regard to nsNIPPV, SNIPPV, and BiPAP, one size does not fit all, that is, subsets of patients may benefit more from one or the other. Quality improvement initiatives may represent a patient-centered approach, including state-of-the-art nursing to optimize pressure transmission, to bi-level NIV.

\section{Conclusion}

Based on this updated review, nsNIPPV and SNIPPV might reduce extubation failure and BPD. Newer machines with flow sensors for SNIPPV delivery should be investigated and attention given to the nursing aspects of providing bi-level NIV including assessing and managing leak. Studies should compare the NIV modalities at equal MAP in order to discern if it is the phasic pressure changes or the higher MAP that is responsible for the apparent benefit of bi-level NIV.

\section{Statement of Ethics}

Not applicable.

\section{Conflict of Interest Statement}

The authors have no conflicts of interest to declare.

\section{Funding Sources}

This research did not receive any specific grant from funding agencies in the public, commercial, or not-for-profit sectors.

\section{Author Contributions}

A.L.S. drafted the article. A.L.S., P.Y.C., and G.M.S. contributed to the conception and design, collection and assembly of literature, analysis and interpretation of the literature, and critical revision of the article for important intellectual content. All the authors approved the article for submission.

\section{References}

1 Kieran EA, Walsh H, O’Donnell CP. Survey of nasal continuous positive airways pressure (NCPAP) and nasal intermittent positive pressure ventilation (NIPPV) use in Irish newborn nurseries. Arch Dis Child Fetal Neonatal Ed. 2011;96(2):F156

2 Owen LS, Morley CJ, Davis PG. Neonatal nasal intermittent positive pressure ventilation: a survey of practice in England. Arch Dis Child Fetal Neonatal Ed. 2008;93(2):F148-50.

3 Vendettuoli V, Bellù R, Zanini R, Mosca F, Gagliardi L, Italian Neonatal N. Changes in ventilator strategies and outcomes in preterm infants. Arch Dis Child Fetal Neonatal Ed. 2014;99(4):F321-4.

4 Roberts CT, Davis PG, Owen LS. Neonatal non-invasive respiratory support: synchronised NIPPV, non-synchronised NIPPV or bi-level CPAP: what is the evidence in 2013?. Neonatology. 2013;104(3):203-9.
5 Schmölzer GM, Kumar M, Pichler G, Aziz K, O'Reilly M, Cheung PY. Non-invasive versus invasive respiratory support in preterm infants at birth: systematic review and metaanalysis. BMJ. 2013;347:f5980.

6 Diblasi RM. Nasal continuous positive airway pressure (CPAP) for the respiratory care of the newborn infant. Respir Care. 2009;54(9): 1209-35.

7 Lin CH, Wang ST, Lin YJ, Yeh TF. Efficacy of nasal intermittent positive pressure ventilation in treating apnea of prematurity. Pediatr Pulmonol. 1998;26(5):349-53.

8 Barrington KJ, Bull D, Finer NN. Randomized trial of nasal synchronized intermittent mandatory ventilation compared with continuous positive airway pressure after extubation of very low birth weight infants. Pediatrics. 2001;107(4):638-41.
9 Davis PG, Morley CJ, Owen LS. Non-invasive respiratory support of preterm neonates with respiratory distress: continuous positive airway pressure and nasal intermittent positive pressure ventilation. Semin Fetal Neonatal Med. 2009;14(1):14-20.

10 Owen LS, Manley BJ. Nasal intermittent positive pressure ventilation in preterm infants: equipment, evidence, and synchronization. Semin Fetal Neonatal Med. 2016;21(3):14653.

11 Mukerji A, Belik J. Neonatal nasal intermittent positive pressure ventilation efficacy and lung pressure transmission. J Perinatol. 2015; 35(9):716-9.

12 Lista G, Castoldi F, Fontana P, Daniele I, Cavigioli F, Rossi $S$, et al. Nasal continuous positive airway pressure (CPAP) versus bi-level nasal CPAP in preterm babies with respiratory distress syndrome: a randomised control trial. Arch Dis Child Fetal Neonatal Ed. 2010; 95(2):F85-9. 
13 Migliori C, Motta M, Angeli A, Chirico G. Nasal bilevel vs. continuous positive airway pressure in preterm infants. Pediatr Pulmonol. 2005;40(5):426-30.

14 Claure N, Bancalari E. Non-invasive ventilation in premature infants. Arch Dis Child Fetal Neonatal Ed. 2015;100(1):F2-3.

15 Mukerji A, Wahab MGA, Mitra S, Mondal T, Paterson D, Beck J, et al. High continuous positive airway pressure in neonates: a physiological study. Pediatr Pulmonol. 2019;54(7): 1039-44.

16 Jane Pillow J. Which continuous positive airway pressure system is best for the preterm infant with respiratory distress syndrome? Clin Perinatol. 2012;39(3):483-96.

17 Klausner JF, Lee AY, Hutchison AA. Decreased imposed work with a new nasal continuous positive airway pressure device. Pediatr Pulmonol. 1996;22(3):188-94.

18 Mukerii A, Shah PS, Shivananda S, Yee W, Read B, Minski J, et al. Survey of noninvasive respiratory support practices in Canadian neonatal intensive care units. Acta Paediatr. 2017;106(3):387-93.

19 Medeiros SK, Carvalho WB, Soriano CF. Practices of use of nasal intermittent positive pressure ventilation (NIPPV) in neonatology in northeastern Brazil. J Pediatr. 2012;88(1): 48-53.

20 Moher D, Liberati A, Tetzlaff J, Altman DG, Group P. Preferred reporting items for systematic reviews and meta-analyses: the PRISMA statement. BMJ. 2009;339:b2535.

21 Ekhaguere O, Patel S, Kirpalani H. Nasal intermittent mandatory ventilation versus nasal continuous positive airway pressure before and after invasive ventilatory support. Clin Perinatol. 2019;46(3):517-36.

22 Higgins JP, Altman DG, Gøtzsche PC, Jüni P, Moher D, Oxman AD, et al. The Cochrane Collaboration's tool for assessing risk of bias in randomised trials. BMJ. 2011;343:d5928.

23 Meader N, King K, Llewellyn A, Norman G, Brown J, Rodgers $\mathrm{M}$, et al. A checklist designed to aid consistency and reproducibility of GRADE assessments: development and pilot validation. Syst Rev. 2014;3:82.

24 Higgins JP, Thompson SG. Quantifying heterogeneity in a meta-analysis. Stat Med. 2002 21(11):1539-58.

25 Chen L, Wang L, Li J, Wang N, Shi Y. Noninvasive ventilation for preterm twin neonates with respiratory distress syndrome: a randomized controlled trial. Sci Rep. 2015;5: 14483.

26 Oncel MY, Arayici S, Uras N, Alyamac-Dizdar E, Sari FN, Karahan S, et al. Nasal continuous positive airway pressure versus nasal intermittent positive-pressure ventilation within the minimally invasive surfactant therapy approach in preterm infants: a randomised controlled trial. Arch Dis Child Fetal Neonatal Ed. 2016;101(4):F323-8.
27 Meneses J, Bhandari V, Alves JG, Herrmann D. Noninvasive ventilation for respiratory distress syndrome: a randomized controlled trial. Pediatrics. 2011;127(2):300-7.

28 Sai Sunil Kishore M, Dutta S, Kumar P. Early nasal intermittent positive pressure ventilation versus continuous positive airway pressure for respiratory distress syndrome. Acta Paediatr. 2009;98(9):1412-5.

29 Shi Y, Tang S, Zhao J, Shen J. A prospective, randomized, controlled study of NIPPV versus nCPAP in preterm and term infants with respiratory distress syndrome. Pediatr Pulmonol. 2014;49(7):673-8.

30 Bisceglia M, Belcastro A, Poerio V, Raimondi F, Mesuraca L, Crugliano C, et al. A comparison of nasal intermittent versus continuous positive pressure delivery for the treatment of moderate respiratory syndrome in preterm infants. Minerva Pediatr. 2007;59(2):91-5.

31 Armanian AM, Badiee Z, Heidari G, Feizi A, Salehimehr N. Initial treatment of respiratory distress syndrome with nasal intermittent mandatory ventilation versus nasal continuous positive airway pressure: a randomized controlled trial. Int J Prev Med. 2014;5(12): 1543-51.

32 Ribeiro SNS, Fontes MJF, Bhandari V, Resende CB, Johnston C. Noninvasive ventilation in newborns $</=1,500 \mathrm{~g}$ after tracheal extubation: randomized clinical trial. Am J Perinatol. 2017;34(12):1190-8.

33 Jasani B, Nanavati R, Kabra N, Rajdeo S, Bhandari V. Comparison of non-synchronized nasal intermittent positive pressure ventilation versus nasal continuous positive airway pressure as post-extubation respiratory support in preterm infants with respiratory distress syndrome: a randomized controlled trial. J Matern Fetal Neonatal Med. 2016;29(10):1546-51.

34 Kahramaner Z, Erdemir A, Turkoglu E, Cosar $\mathrm{H}$, Sutcuoglu S, Ozer EA. Unsynchronized nasal intermittent positive pressure versus nasal continuous positive airway pressure in preterm infants after extubation. J Matern Fetal Neonatal Med. 2014;27(9):926-9.

35 Ramanathan R, Sekar KC, Rasmussen M, Bhatia J, Soll RF. Nasal intermittent positive pressure ventilation after surfactant treatment for respiratory distress syndrome in preterm infants $<30$ weeks' gestation: a randomized, controlled trial. I Perinatol. 2012; 32(5):336-43

36 Komatsu DF, Diniz EM, Ferraro AA, Ceccon ME, Vaz FA. Randomized controlled trial comparing nasal intermittent positive pressure ventilation and nasal continuous positive airway pressure in premature infants after tracheal extubation. Rev Assoc Med Bras. 2016; 62(6):568-74.
37 Kirpalani H, Millar D, Lemyre B, Yoder BA, Chiu A, Roberts RS, et al. A trial comparing noninvasive ventilation strategies in preterm infants. N Engl J Med. 2013;369(7):611-20.

38 Silveira CS, Leonardi KM, Melo AP, Zaia JE, Brunherotti MA. Response of preterm infants to 2 noninvasive ventilatory support systems: nasal CPAP and nasal intermittent positivepressure ventilation. Respir Care. 2015; 60(12):1772-6.

39 Kugelman A, Feferkorn I, Riskin A, Chistyakov I, Kaufman B, Bader D. Nasal intermittent mandatory ventilation versus nasal continuous positive airway pressure for respiratory distress syndrome: a randomized, controlled, prospective study. J Pediatr. 2007; 150(5):521-e1.

40 Moretti C, Giannini L, Fassi C, Gizzi C, Papoff P, Colarizi P. Nasal flow-synchronized intermittent positive pressure ventilation to facilitate weaning in very low-birthweight infants: unmasked randomized controlled trial. Pediatr Int. 2008;50(1):85-91.

41 Friedlich P, Lecart C, Posen R, Ramicone E, Chan L, Ramanathan R. A randomized trial of nasopharyngeal-synchronized intermittent mandatory ventilation versus nasopharyngeal continuous positive airway pressure in very low birth weight infants after extubation. J Perinatol. 1999;19(6 Pt 1):413-8.

42 Khalaf MN, Brodsky N, Hurley J, Bhandari V. A prospective randomized, controlled trial comparing synchronized nasal intermittent positive pressure ventilation versus nasal continuous positive airway pressure as modes of extubation. Pediatrics. 2001;108(1):13-7.

43 Zhou B, Zhai JF, Jiang HX, Liu Y, Jin B, Zhang YY, et al. Usefulness of DuoPAP in the treatment of very low birth weight preterm infants with neonatal respiratory distress syndrome. Eur Rev Med Pharmacol Sci. 2015;19(4):5737.

44 Victor S, Roberts SA, Mitchell S, Aziz H, Lavender T, Extubate Trial G. Biphasic positive airway pressure or continuous positive airway pressure: a randomized trial. Pediatrics. 2016 138(2):e20154095

45 O'Brien K, Campbell C, Brown L, Wenger L, Shah V. Infant flow biphasic nasal continuous positive airway pressure (BP- NCPAP) vs. infant flow NCPAP for the facilitation of extubation in infants' $\leq 1,250 \mathrm{~g}$ : a randomized controlled trial. BMC Pediatr. 2012;12:43.

46 Buzzella B, Claure N, D’Ugard C, Bancalari E. A randomized controlled trial of two nasal continuous positive airway pressure levels after extubation in preterm infants. J Pediatr. 2014;164(1):46-51.

47 Lemyre B, Davis PG, de Paoli AG. Nasal intermittent positive pressure ventilation (NIPPV) versus nasal continuous positive airway pressure (NCPAP) for apnea of prematurity. Cochrane Database Syst Rev. 2002(1):CD002272. 